\title{
RAÇA E MODERNIDADE EM FORMAÇÃO DO BRASIL CONTEMPORÂNEO, DE CAIO PRADO JR.*
}

\section{Alfredo Cesar B. de Melo}

https://orcid.org/0000-0002-7038-5749

Universidade Estadual de Campinas (Unicamp), Campinas - SP, Brasil. E-mail: alfmelo@unicamp.br

DOI: $10.1590 / 3510215 / 2020$

Caio Prado Júnior (1907-1990), em Formação do Brasil contemporâneo (1942), clássico ensaio de interpretação nacional, buscou apreender os traços remanescentes da colonização que ainda estruturariam e condicionariam a vida social brasileira. Para o autor, era comum perceber no Brasil de seus dias "a presença de uma realidade já muito antiga que não é senão aquele passado colonial” (Prado Jr., 2000 , p. 3). É certo também que estávamos viven-

* A primeira versão deste artigo foi redigida em Portugal, em estágio pós-doutoral na Universidade Nova de Lisboa, financiado pela Coordenaçáo de Aperfeiçoamento de Pessoal de Nível Superior (Capes). O tema da nossa investigação era a ideologia do progresso no Brasil. Em um momento de crise e ameaça à existência das agências federais de fomento, reitero meu agradecimento à Capes. Agradeço aos comentários e às sugestóes dos cinco pareceristas anônimos e à revisão cuidadosa de Cátia de Almeida.

Artigo recebido em: 26/10/2017

Aprovado em: 08/09/2019 do em tempos marcados por intensa transformação que começava a acontecer, "seja por força própria, seja pela intervenção de novos fatores estranhos" (Idem, p. 3). Para usar as palavras de Prado Jr., "este novo processo histórico [de transformação] se dilata, se arrasta[ndo] até hoje" (Idem, p. 3), sem chegar a seu termo. O Brasil colonial persistia, impedindo a emergência de um Brasil nação.

Segundo Bernardo Ricupero, estes são alguns dos temas centrais da obra caiopradiana: a transição de colônia para nação, de certo arcaísmo social para modernidade, de jugo oligárquico para uma cultura mais democrática (2000, p. 160). Pode-se dizer, aliás, que a obsessão pelo tema da transição social no Brasil era partilhada por outros intérpretes do Brasil coetâneos de Prado Jr., nos intrépidos e revolucionários anos de 1930. Pessoas como Sérgio Buarque de Holanda, para quem "estaríamos vivendo entre dois mundos: um definitivamente morto e outro que luta por vir à luz" (Holanda, 1995, p. 180). Prado Jr. cer- 
tamente discordaria da ênfase buarqueana, pois não identificava na matriz colonial brasileira um mundo morto e com certeza antevia uma luta muito mais renhida e difícil para que o outro mundo - o da nação moderna - viesse à luz.

Glosando a obra Formação do Brasil contemporâneo, Roberto Schwarz afirma que, para Prado Jr., "não seríamos uma nação independente - a despeito do Grito do Ipiranga - enquanto não corrigirmos as deformaçóes que constituem o nosso legado colonial" (1999, p. 18). Remover os obstáculos produzidos pelo passivo colonial implicava tomar um conjunto de medidas coordenadas: fazer uma crítica contundente ao imperialismo, realizar uma reforma agrária que promovesse uma agricultura diversificada e intensiva, implementar políticas econômicas que fortalecessem o mercado interno brasileiro e, last but not least, modernizar culturalmente o país.

A maior parte dos estudiosos da obra de Prado Jr. tem destacado as dimensóes socioeconômicas do esforço em combater os fortes resquícios coloniais da sociedade brasileira. Menor atenção tem sido dada ao aspecto cultural de tal estratégia modernizadora, que teria como finalidade última, nas palavras de Prado Jr., "estimular o levantamento dos nossos padrốes culturais” (2012, p. 273).

Neste artigo, pretendemos discutir como em seu clássico ensaio de interpretação do Brasil Prado Jr. concebe o aggiornamento cultural brasileiro passo imprescindível para o país adentrar na modernidade - com base em um esquema interpretativo fulcrado no racismo cultural. ${ }^{1}$ Argumentamos que Formação do Brasil contemporâneo estabelece uma clara hierarquização de culturas para interpretar o Brasil, em que a ocidental assume o protagonismo das transformaçóes históricas, ao passo que as culturas não ocidentais da matriz colonial brasileira (africanas e ameríndias) são avaliadas como coadjuvantes de pouca expressão, sem muito a contribuir, além da força física, para a construção do Brasil moderno. Para esclarecer tal argumento, realizamos o seguinte caminho analítico: mostramos os posicionamentos dos estudiosos que trataram do tema do racismo no reconhecido ensaio de interpretaçáo de Prado Jr. para mapear o terreno da discussão; em seguida, propomos uma discussão sobre o conceito de racismo cultural; por fim, examinamos como tal categoria é utilizada na interpretação caiopradiana do Brasil e quais as consequências políticas desse emprego conceitual.

\section{Racismo visto pela fortuna crítica}

Podemos dizer, esquematicamente, que o racismo na obra de Prado Jr. é tratado de três maneiras distintas por aqueles que se dedicam a seu estudo. Há os que não apenas ignoram o tema como também veem em Prado Jr. um autor que superou o pensamento racista; aqueles que identificam a questão, mas tendem a minimizá-la como aspecto sem maior relevância na obra do autor; e existem os que ressaltam o tema como algo importante a ser considerado e discutido. ${ }^{2}$

No primeiro grupo, podemos encontrar intelectuais como Dante Moreira Leite, Emília Viotti da Costa e Antonio Candido. Em seu clássico O caráter nacional brasileiro, Leite classifica a interpretação marxista da história brasileira levada a cabo por Prado Jr. como "superação das ideologias" (1976, p. 356), uma vez que, ao contrário de outros intérpretes do Brasil que buscavam atribuir traços psicológicos e a-históricos a um brasileiro abstrato e sem clivagens de classe, Prado Jr. realizou uma interpretação detida nas relaçóes sociais geradas pelo quadro geral do colonialismo. Para Costa, o grande mérito da explicação do Brasil proposta por Prado Jr. foi não ter se fiado na subjetividade senhorial - cheia de preconceitos de classe e raça - para procurar "no jogo das contradiçóes objetivas o sentido do processo" (1998, p. 126). Algo semelhante se passa no elogio que Candido a Formaçáo do Brasil contemporâneo por sua "exposição do tipo factual, inteiramente afastada do ensaísmo [...] e visando a convencer pela massa do dado e do argumento" (1995, p. 11). Para esse grupo de intelectuais, a objetividade da análise histórica de Prado Jr. coloca Formação do Brasil contemporâneo em um patamar acima das outras interpretaçóes do Brasil, distanciando-se dos retratos impressionistas do país, repletos de deformaçôes epistemológicas, estereótipos raciais e essencializaçóes de vários tipos. A obra de Prado Jr. seria um ponto de ruptura com a tradição ensaística brasileira. ${ }^{3}$ 
O outro grupo percebe a presença de um vocabulário racista na obra de Prado Jr., sobretudo quando o autor se refere a africanos e ameríndios como "raças inferiores" dominadas pelo português ou quando as avalia como "bárbaras e semibárbaras” (2000, p. 280). No entanto, esse grupo, que tem entre seus expoentes Francisco Iglésias, Carlos Guilherme Mota e Bernardo Ricupero, considera que tais escolhas de palavras não comprometem o valor da interpretação do Brasil realizada por Prado Jr. em Formaçáo do Brasil contemporâneo nem assumem dimensão relevante para explicar a visão caiopradiana do processo modernizador que deveria ocorrer no Brasil. Iglésias julga que "o capítulo sobre raças e o livro no conjunto são corretos" (1982, p. 24) a despeito das passagens racistas que, na leitura desse autor, "podem ser vistas como cochilos ou falta de vigilância mais rigorosa" (Idem, p. 24). Iglésias ainda comenta que Prado Jr. seguramente foi alertado sobre o cochilo, mas "[c]onsiderou a questão de somenos" (Idem, p. 24). Mota segue o mesmo padrão argumentativo, elogiando a obra principal de Prado Jr., ainda "que pesem alguns deslizes dados por fórmulas e valores pouco satisfatórios que perpassavam a intelligentsia em geral” (2008, p. 74). As inescapáveis contingências históricas que fazem Prado Jr. ser um homem de seu tempo (racista) também está no argumento desenvolvido por Ricupero, que acredita que "mesmo alguém tão perceptivo como Caio Prado é incapaz de fugir inteiramente ao racismo predominante na época em que escreve" (2000, p. 144). Pressupóe-se que o racismo na obra principal de Prado Jr. é uma crosta anacrônica acoplada à análise histórica materialista do Brasil, passível de ser removida sem que haja grande prejuízo à compreensão geral que temos de sua obra.

O terceiro grupo de pensadores denuncia o racismo de Prado Jr. de modo contundente. É o caso de intelectuais fora da órbita uspiana, como Silviano Santiago e Ronaldo Vainfas. Santiago procura compreender o racismo de cunho cultural na obra de Prado Jr., "nosso primeiro grande pensador marxista" (2000, p. 24), como um produto do "eurocentrismo comum aos pensadores radicais do Iluminismo que se fecham com relação ao outro, para hierarquizar e poder mais convincentemente se colocar no centro e desqualificar o que lhe é diferente" (2006, p. 140, grifo do autor). Por sua vez, Vainfas chama de "aviltante" (1999, p. 7) o racismo encontrado nas páginas de Formação do Brasil contemporâneo. Ainda de acordo com o argumento desse autor, o marxismo de Prado Jr. convivia com a "raciologia científica" típica do século XIX, levando-o a "reiterar preconceitos antigos" (Idem, p. 7).

Os três posicionamentos descritos oferecem um mapa que permite ressaltar nosso ponto de vista acerca do tema do racismo no clássico ensaio de Prado Jr. A nosso ver, os três posicionamentos parecem insatisfatórios ${ }^{4}$. Vejamos: (1) as evidências textuais do racismo de Prado Jr., conforme procuramos mostrar, são muito sólidas para que se continue defendendo a tese de que Formação do Brasil contemporâneo tenha superado o racismo; (2) do mesmo modo, a razão principal deste artigo é mostrar que o racismo não é um elemento periférico, fruto de um descuido, e, por isso, irrelevante no pensamento social de Prado Jr., pelo contrário, pretendemos destacar que se trata de um aspecto central de seu modo de imaginar o Brasil; (3) é necessário ir além da mera caracterização e denúncia do racismo na obra desse autor. Precisamos compreender o sentido político subjacente a esse modo de hierarquizar as culturas de grupos étnico-raciais e como o racismo cultural e o progressismo se juntam na prosa caiopradiana ao pensar a inserção da sociedade brasileira na modernidade.

\section{Racismo cultural}

A discussão sobre racismo cultural aparece com maior densidade nos anos posteriores à descolonização dos países africanos e asiáticos, em decorrência da migração de muitos habitantes das ex-colônias para os antigos centros metropolitanos europeus. O filósofo francês Étienne Balibar chegou a classificá-lo como "neorracismo"; seria um "racismo sem raça” (1991, p. 23), cujo foco dominante não estaria na herança biológica, mas nas diferenças culturais consideradas insuperáveis.

É preciso, no entanto, ser criterioso em relação à novidade desse racismo. $\mathrm{O}$ fenômeno recente seria a dinâmica reativa e defensiva de tal modo de 
hierarquizar grupos humanos segundo suas culturas, isto é, a reação de uma Europa que se sentia acuada pelo fluxo migratório, imaginando-se ameaçada de perder sua identidade cultural, em decorrência da vinda em massa de estrangeiros. Em um contexto de suposta crise identitária, limites devem ser impostos para ressaltar a incompatibilidade entre o estilo de vida do europeu e as práticas culturais dos não ocidentais que passam a habitar o espaço da antiga metrópole.

O racismo cultural do qual tratamos a seguir é aquele que, longe de jogar na retranca, assume-se como um farol civilizatório. Nesse caso, a hierarquização de culturas é clara e se apresenta como fiadora benigna de um futuro melhor, quando as diversas culturas do globo convergirem para padróes civilizados de vida social, até então restritos a alguns povos europeus.

Um dos mais destacados publicistas do Iluminismo, Marie-Jean-Antoine-Nicolas de Caritat, o marquês de Condorcet, esperava que as naçóes um dia se aproximassem "do estado de civilização a que chegaram os povos mais esclarecidos, os mais livres, os mais libertos de preconceito, os franceses e ingleses" (2013, p. 190). Supunha que, com a marcha do progresso, esvaneceria a "distância imensa que separa esses povos [franceses e ingleses] da servidão dos hindus, da barbárie das tribos africanas, da ignorância dos selvagens" (Idem, p. 190). No argumento de Condorcet, não há nada de intrinsecamente racial ou biológico que explique a suposta liberdade de franceses e ingleses nem a servidão, barbárie e ignorância atribuídas aos povos não ocidentais. São todas características imputadas aos estoques culturais de cada povo, dispostos em uma nítida hierarquia, que tem a cultura europeia em seu topo. De acordo com a premissa progressista, todos os seres humanos, independentemente de cultura e nível social, possuem as mesmas capacidades morais e cognitivas para se aperfeiçoar, isto é, para chegar ao mesmo nível cultural da Europa moderna. O racismo cultural está inequivocamente associado à ideologia do progresso.

Quase duzentos anos depois, Frantz Fanon avaliou os pressupostos do racismo cultural de um ângulo anticolonial. Para ele, "o racismo burguês ocidental com relação ao negro e ao árabe é um ra- cismo de desprezo; é um racismo que minimiza" a cultura dos negros e árabes (Fanon, 1968, p. 135). No entanto, destaca que, apesar do desdém pela vida cultural dos colonizados, a ideologia burguesa proclamava "uma igualdade de essência entre os homens", convidando "os sub-homens a se humanizarem através do tipo de humanidade ocidental que ela encarnava" (Idem, p. 135).

Com base no argumento de Fanon, podemos sublinhar uma diferença básica entre o "neorracismo" e o racismo cultural pós-iluminista: se no primeiro caso as diferenças culturais passam a ser consideradas intransponíveis, no segundo, o despojamento da cultura original (sempre desprezada) e a consequente adesão à cultura ocidental são gestos encorajados. O devir-ocidental se figura como um movimento irrefreável e desejável, funcionando como engrenagem primordial da ideologia do progresso. Assim, toda aproximação a um suposto e idealizado modo ocidental de estar no mundo com sua disciplina corporal, sua ética de trabalho, seu método racional de administrar a vida social e econômica, seu conhecimento científico, sua cultura democrática etc. - passa a ser vista como avanço e melhoramento.

No Brasil, há uma longa tradição intelectual que orbita em torno da ideia da formação, que pressupóe um eterno devir de algo que ainda não somos, mas que gostaríamos de ser: uma nação moderna, isto é, uma sociedade dentro dos parâmetros ocidentais, mas com modulação nacional. Tal desejo tem mobilizado a imaginação brasileira e é, até hoje, um dos temas centrais de nosso pensamento social. Neste artigo estudamos um tópico menos visitado quando tratamos da ideia de formação: tâo importante quanto apreender qual país a elite intelectual quer construir é examinar que outras possibilidades (outros devires) de Brasil tal elite nega, desqualifica, despreza, e analisar como o imbricamento entre essas duas virtualidades - o devir desejado e o devir rejeitado para o país - está ligado a uma visão hierárquica de culturas, segundo a qual, algumas delas, as europeias, vão nos ajudar a adentrar na modernidade em detrimento de outras, inferiores e menos elaboradas, que nos impedem de chegar lá ou nos mantêm aprisionados em um atraso vergonhoso. 5 
Para ilustrar essa questão, analisamos um comentário de José Bonifácio de Andrada e Silva, estadista e publicista luso-brasileiro, considerado pela historiografia como um dos mentores da Independência política do Brasil. Em um de seus "Apontamentos para a civilização dos índios bravos do Império do Brasil", apresentado na Assembleia Constituinte de 1823, Andrada e Silva defendeu a plena capacidade de o ameríndio integrar-se à sociedade brasileira. Argumenta que, se Isaac Newton tivesse nascido "entre os guaranis, seria mais um bípede que pisara sobre a superfície da Terra”, enquanto "um guarani criado por Newton talvez ocupasse o seu lugar" (Andrada e Silva, 2000, p. 50). Newton e os guaranis só teriam em comum a dimensão mais elementar da humanidade, ou seja, eram bípedes que habitavam a Terra, já que o estoque cultural do primeiro, na visão eurocêntrica de Andrada e Silva, seria vastamente superior ao do segundo. Se Newton tivesse nascido entre os guaranis (devir-índio), não teria feito sua contribuição à humanidade. Porém, ainda de acordo com esse raciocínio, um guarani poderia, se bem instruído por Newton, chegar ao mesmo nível do mestre. Para Andrada e Silva, e para a elite intelectual brasileira, o devir-ocidental seria a chave para alcançar o protagonismo da história, ou melhor, para efetivamente entrar na História.

Aproximadamente 150 anos separam os epígonos iluministas do marquês de Condorcet - como Andrada e Silva -, detentores da crença na perfectibilidade da humanidade, e a obra do marxista Prado Jr. A ideia de que seres humanos dispóem de uma unidade psíquica, monogenista por excelência, é trabalhada ao longo do século XIX por evolucionistas vitorianos, como Edward Burnett Tylor e Lewis Henry Morgan. Por meio do método comparativo, os evolucionistas passaram a enxergar as "várias sociedades existentes no mundo contemporâneo" como representantes de "diferentes estágios no progresso da humanidade”, como selvageria, barbárie e civilização, transformando assim sincronia em diacronia (Stocking Jr., 1968, p. 114). Outra tese basilar defendida pelo evolucionismo cultural é a da importância do ambiente para a ascensão cultural das raças tidas como culturalmente atrasadas. $\mathrm{O}$ sociólogo inglês Herbert Spencer, bastante influente nas ciências sociais até o primeiro quartel do século $\mathrm{XX}$, afirmou em seu The principles of sociology que o desenvolvimento das faculdades intelectuais andava de mãos dadas, pari passu, com os avanços sociais. Em raciocínio reverso, argumentou que os primitivos eram incapazes de desenvolver tais faculdades mentais, uma vez que não viviam em um ambiente adequado; destacou ainda que só o progresso poderia acionar essas capacidades de evolução das faculdades intelectuais (Spencer, 1882, p. 110).

O racismo cultural é, portanto, um produto pós-iluminista derivado do evolucionismo cultural, em sua variante progressista, que apresenta estas características básicas: (1) crença na unidade psíquica da humanidade; (2) enquadramento da variedade cultural em moldura hierárquica, postulando não apenas existência de raças culturalmente "superiores" e "inferiores" como também colocando marcadores supostamente diacrônicos entre elas, performando um arco que vai do "selvagem" ao "civilizado", passando pelo "bárbaro"6; (3) defesa do ambiente como fator preponderante para a evolução social ocorrer, isto é, a mudança progressiva de estágio cultural.

Prado Jr. entra em contato com muitas dessas concepçóes que articulam o racismo cultural por meio da antropologia francesa. Como mostra Paulo Teixeira Iumatti (2018), Prado Jr. leu George Montandon, autor de L'Ologenèse culturelle, traité d'ethnologie (1934) e Lucien Levy-Bruhl, que publicou Les fonctions mentales dans les societés inférieures (1922) ${ }^{7}$. Iumatti salienta que, apesar de Prado Jr. não ser um evolucionista tout court, utilizava frequentemente esquemas de interpretação evolucionistas.

Pretendemos mostrar, a seguir, como tais dimensôes do racismo cultural operam em Formação do Brasil contemporâneo e quais são as consequências desse emprego conceitual para a compreensão daquilo que é proposto pela obra de Prado Jr..

\section{O racismo cultural em Formaçáo do Brasil contemporâneo, de Caio Prado Júnior}

A narrativa tecida em Formação do Brasil contemporâneo está estruturada por determinados valores que auxiliam Prado Jr. a apreender, na história 
brasileira, um sentido para o processo social que constituiu o país. Longe de ser uma exposição do "tipo factual, inteiramente afastada do ensaísmo", como sugere Candido (1995, p. 11), é possível entrever na obra de Prado Jr. uma subjetividade que não cessa de identificar e avaliar quais seriam, de um lado, os obstáculos e, de outro, os possíveis estímulos à formação de uma nação moderna no Brasil. Os obstáculos passam a ser severamente criticados, enquanto os incipientes estímulos são destacados positivamente. Formação do Brasil contemporâneo é narrado da perspectiva de quem vislumbra para o Brasil a modernidade como ponto de chegada (devir-ocidental), ainda que tal ponto se encontre distante e seja de difícil acesso.

Pensemos no capítulo "Raças" de Formação do Brasil contemporâneo. Encontramos lá uma forte empatia de Prado Jr. pelo encaminhamento que a legislação pombalina dera ao chamado "problema indígena” (Prado Jr., 2000, p. 86). Isso acontece porque, na visão de Prado Jr., a nova legislação permitia que os índios se preparassem para a vida civilizada, sem perder "a comunhão colonial” (Prado Jr., 2000, p. 89). Tal comunhão implicava a imposição da língua portuguesa e o fomento do "maior intercâmbio possível” (Idem, p. 80) entre índios e portugueses, em uma clara referência à miscigenação. A nova política ia de encontro àquela realizada pelos jesuítas, que promovia o isolamento dos índios. Para Prado Jr., "sem a providência das leis pombalinas", aqueles aldeamentos administrados pelos jesuítas evoluiriam "numa direção inteiramente diversa e não chegaria[m] nunca a fazer parte do país” (Idem, p. 93). Assim, está dado o exemplo de como a escala de valores de Prado Jr. aparece em sua análise da história do Brasil: as medidas que objetivavam a integração do índio à cultura do colonizador eram avaliadas positivamente, enquanto o modo de os jesuítas colonizarem os nativos era rechaçado por apartá-los do convívio com a sociedade colonial e servir de semente de uma organização social estranha aos interesses da colonização. O ponto de fuga do processo histórico-social do Brasil (o devir de nossa formação), na óptica de Prado Jr., é a sociedade nacionalmente organizada e culturalmente integrada e é com base nessa posição que narra a história brasileira, destacando quais sáo as forças que impulsionam (as me- didas pombalinas de integração dos índios) e quais emperrariam (a colonização jesuíta, marcada pelo isolamento do nativo) a sociedade colonial na caminhada para a formação nacional.

De acordo com esse esquema interpretativo, um dos principais problemas criados pela colonização foi colocar no mesmo território, em intensa convivência, raças com estoques culturais muito inferiores aos dos europeu, já que os indígenas da América e os negros africanos eram "povos de nível cultural ínfimo, comparado a de seus dominadores" (Prado Jr., 2000, p. 280). Era preciso sincronizar as temporalidades das raças que construíam o Brasil. Baseado nesse diagnóstico, surgiu o imperativo do aggiornamento cultural, isto é, elevação do nível cultural do povo brasileiro, forjado por essas raças culturalmente inferiores. O vocabulário utilizado para referir-se a essa atualizaçâo cultural é variado: integração, incorporação, absorção, transição.

Ainda no capítulo "Raças", Prado Jr. avalia de modo positivo a mestiçagem exatamente por ter auxiliado nesse processo de integração cultural. $\mathrm{O}$ amálgama de raças é analisado menos como uma mistura entre etnias e mais como consolidação de uma hegemonia cultural produzida pelo grupo dominante e minoritário, os portugueses. Para o autor:

Graças a ela [a mestiçagem], o número relativo pequeno de colonos brancos que veio povoar o território pôde absorver as massas consideráveis de negros e índios que para ele afluíram ou nele já se encontravam, pôde impor seus padróes e cultura à colônia, que mais tarde, embora separada da mãe-pátria, conservará os caracteres essenciais da sua civilizaçáo (Prado Jr., 2000, p. 102).

Notemos que o comentário acerca da mestiçagem, nesse trecho, nada mais é que uma definição básica de colonização: um diminuto grupo dominante consegue absorver as massas não ocidentais, impondo-lhes um padrão de cultura ocidental e estabelecendo uma relação de continuidade espiritual entre a jovem nação e a "mãe-pátria". Vemos, ainda, um elogio à eficácia da técnica de dominação que estava embutida no processo de miscigenação. Um tom semelhante pode ser identificado em um 
trecho em que Prado Jr. relata a mortandade dos ameríndios gerada pelo contato entre o europeu e o nativo, seja por atos deliberados de violência, seja como consequência de várias moléstias transmitidas pelo branco ao indígena sem imunidade. $\mathrm{O}$ relato é feito de tal modo que o genocídio dos índios aparece figurado como uma fatalidade do processo civilizatório. Segundo Prado Jr.:

A população indígena, em contato com os brancos, vai sendo progressivamente eliminada e repetindo mais uma vez um fato que sempre ocorreu, em todos os lugares e em todos os tempos em que se verificou a presença, uma ao lado da outra, de raças de níveis culturais muito apartadas: a inferior e a dominada desaparece. E não fosse o cruzamento, praticado em larga escala entre nós e que permitiu a perpetuação do sangue indígena, este estaria fatalmente condenado à extinção total $\left(2000\right.$, p. 102) ${ }^{8}$.

A miscigenação é elogiada como técnica de dominação e o genocídio é visto como resultado infeliz de um desenvolvimento histórico inevitável (o devir-ocidental). Por meio de dois ângulos diferentes, observamos como Prado Jr. narra a supressão da cultura ameríndia, como se não coubesse no futuro do país. O que permite a "perpetuação do sangue indígena" é o cruzamento entre raças, garantindo ao índio uma sobrevivência parcial, por ser meramente genética. $\mathrm{O}$ sangue indígena persiste, mas em um corpo que agora habita um espaço e uma cultura construídos com base em premissas europeias, já que, na gramática caiopradiana, a miscigenação significa o triunfo hegemônico da cultura portuguesa sobre "a massa considerável de negros e índios” (Prado Jr., 2000, p. 102).

Se a colonização recebe um tratamento entre ameno e elogioso quando parece preparar o terreno para a modernidade ocidental, outro tom é adotado por Prado Jr. quando o processo colonizador passa a ser visto como o grande produtor de obstáculos para a consolidação de uma nação com padróes modernos de sociabilidade. Desse modo, adentramos um terreno mais conhecido e exaltado da obra desse autor, o da crítica ao passivo criado pelo sentido de nossa colonização.
Para Prado Jr., "a colonização produziu seus frutos quando reuniu neste território imenso e quase deserto, em 300 anos de esforços, uma população catada em três continentes, e com ela formou um conjunto social" com "traços inconfundíveis". Ademais, o processo colonizador "devassou a terra, explorou o território, e nele instalou aquela população" para, depois, remeter "por cima do oceano, para os mercados da Europa, caixas de açúcar, rolos de tabaco, fardos de algodão, barras de ouro e pedras preciosas". No entanto, à medida que a colonização se consolidava, um "passivo considerável” era acumulado, atuando como empecilho para a formação de um Brasil moderno. Tal passivo era formado por elementos que se "revelariam vícios profundos e orgânicos". São muitos os fatores elencados pelo autor que travavam o desenvolvimento do país. Nesta passagem em particular, cita dois desses "vícios profundos": "a incorporação apressada de raças e culturas tão diferentes entre si” e o "trabalho servil" (Prado Jr., 2000, p. 366). É importante observar que, no rol dos entraves à construção da nação, as diferenças culturais entre as raças formadoras do Brasil estão aparentemente no mesmo plano que a escravidáo, o que mostra a centralidade, para Prado Jr., da questáo do atraso cultural para compreender os impasses do país.

Devemos ressaltar que a suposta incultura do Brasil não seria primordialmente, para Prado Jr., um produto do trabalho escravo, mas, antes, o resultado da atuação das culturas inferiores que engendraram a população brasileira. A escravidão potencializava e aumentava essa incultura, uma vez que a cruenta instituição inviabilizava o resgate civilizatório das populações consideradas "semibárbaras". Segundo o autor, o regime servil não apenas degradava as relaçóes sociais, desumanizava o negro, corrompia a moral e os costumes, desencorajava o trabalho como também comprometia a integração das raças de cultura inferior, atravancando nosso devir-ocidental. De acordo com ele, a escravidão "[i]ncorporou à colônia, ainda em seus primeiros instantes, e em proporçóes esmagadoras, um contingente estranho e heterogêneo de raças que beiravam ainda o estado de barbárie" (Prado Jr., 2000, p. 283). A grande crítica que Prado Jr. faz à colonização incide na maneira como tal contin- 
gente populacional acaba sendo incorporado a uma atividade econômica, submetido na condição de escravizado, sem que qualquer estratégia fosse pensada para integrá-lo cultural e socialmente ao país que o recebia. Não houvera transição ou "estágio preparatório” (Idem, p. 283). O índio, pondera Prado Jr., ao menos recebera alguma educação jesuítica, trazendo-lhe "um começo de preparação" para a vida civilizada (Idem, p. 283). O negro, por sua vez, "não teve no Brasil a proteção de ninguém", tratado "com o último dos descasos no que diz respeito à sua formação moral e intelectual, e preparação para a sociedade que à força o incluíram" (Idem, p. 284).

Prado Jr. concordava com a premissa freyreana de que era necessário distinguir o "negro" do "escravo" (2000, p. 355). Ao longo de sua análise, no entanto, a distinção não funciona de modo satisfatório porque, ao contrário de Gilberto Freyre, não valoriza a cultura do negro no período anterior à escravidão. ${ }^{9}$ Vejamos um exemplo: o autor de Formação do Brasil contemporâneo afirma que "o cabedal que [o escravo] traz consigo da selva americana ou africana, e que [ele, Prado Jr.,] não quer subestimar, é abafado, e se não aniquilado, deturpa-se pelo estatuto social, material e moral a que se vê reduzido seu portador" (Idem, p. 280). Em outro trecho, conclui que, "se o negro traz algo positivo, isto se anulou na maior parte dos casos" (Idem, p. 355). As passagens destacadas, nas quais Prado Jr. parece lançar o benefício da dúvida em relação ao valor cultural dos africanos, não foram desenvolvidas posteriormente e parecem estar isoladas, pois, no decorrer de sua obra principal, não identificou qualquer elemento positivo nas culturas africanas, cujas contribuições são frequentemente subestimadas e menosprezadas, tidas como selvagens e bárbaras. O que esperar de positivo vindo do negro ou índio escravizado se a contribuição deles para formação brasileira, na visão do autor, "é além daquela energia motriz quase nula" (Idem, p. 280)? Quando o assunto é a relação entre a cultura do negro (e do ameríndio) e o trabalho servil, o essencial da formulação caiopradiana não está na denúncia de que a escravidão arruinou o universo cultural do negro (considerado, de partida, como algo de valor ínfimo), mas na maneira como a sociedade escravocrata sabotou o devir-ocidental do negro brasileiro.
E nesse ponto discordamos de Iumatti quando vê "duas tendências contraditórias" no argumento de Prado Jr.: "de um lado, Caio Prado destaca a opressão que a ordem colonial impunha aos grupos escravizados ou desprezados", enquanto, de outro lado, o historiador aponta o nível cultural desses grupos sociais "como fator de sua inferioridade, culpabilizando, assim, de forma involuntária e em certa medida, os próprios oprimidos" (2018, p. 387). Como observamos, tanto a crítica à escravidão como a visão hierárquica dos níveis culturais guardam entre si uma sólida coerência interna. A violência inerente à escravidão desumaniza e impede contingentes de população "semibárbaras" de transitarem para a vida moderna. O nexo progressista do raciocínio é evidente, já que o metro normativo do progresso serve, a um só tempo, para combater a ignomínia da escravidão e para apresentar-se como farol civilizatório ou ponto de chegada para os povos supostamente atrasados.

Conforme pontuamos, Prado Jr. critica o baixo nível cultural dos povos não ocidentais que, com os portugueses, formaram o Brasil; também avalia de modo bastante negativo a escravidão por destruir os canais de transição desses povos à vida moderna. A pergunta que resta é: qual fator - o baixo nível cultural do povo e a escravidão - atua de modo mais preponderante para explicar os problemas da formação social brasileira? A resposta a tal questão é valiosa já que nos permite verificar o peso dessa hierarquia cultural na interpretação que Prado Jr. faz do legado colonial. A hipótese que desenvolvemos neste artigo é a de que tais fatores desfrutam de relativa autonomia na explicação do atraso brasileiro, mas o aspecto cultural ainda sobrepuja a dimensão do trabalho escravo.

É importante ressaltar que o "trabalho servil" e a "incorporação apressada de raças e culturas tão diferentes entre si” (Prado Jr., 2000, p. 366) são facetas entrelaçadas do mesmo fenômeno que, por sua vez, só pode ser compreendido quando levamos em conta o sentido da colonizaçáo entrevisto por Prado Jr. A questão está formulada no primeiro capítulo de Formação do Brasil contemporâneo, quando o autor salienta o caráter mercantil da colonização brasileira: "empresa do colono branco, que reúne à natureza, pródiga em recursos aproveitáveis 
para produção de gêneros de grande valor comercial, o trabalho recrutado entre raças inferiores que domina: indígenas ou negros africanos importados" (Prado Jr., 2000, p. 19). A colônia seria, então, uma unidade produtora forjada pelo trabalho escravo de raças inferiores.

A crítica aos legados da escravidão já foi citada anteriormente e reitera aquelas já feitas por outros, como Joaquim Nabuco: a escravidão acabava por desvalorizar o trabalho, desestimulava o empreendimento econômico, corrompia de forma pervasiva as relaçóes sociais etc. Já a convivência entre raças com estágios culturais diferentes tinha como resultado o baixo nível da imensa maioria da população, que pode ser verificado não apenas por meio do parco repertório cultural dessa população como também pela destacada ineficiência nas atividades de trabalho e produção, "entregues como estavam a pretos boçais e índios apáticos" (Prado Jr., 2000, p. 283). Parece claro para Prado Jr. que, apesar da colonização ser um derivado da expansão comercial europeia e ter sido comandada por um povo ocidental, o trabalho propriamente dito era executado por povos não ocidentais atrasados ("pretos boçais e índios apáticos”), que, no início da empreitada agromercantil, eram vistos como fatores de produção (mão de obra escrava), mas que ao longo do processo histórico que culminou na Independência passaram a ser lentamente compreendidos como parte do povo da nação.

O baixo nível cultural do povo é explicado pelo barbarismo das raças formadoras que nunca puderam se elevar, impedidas que estavam pelo obstáculo da escravidão. A transição que levaria o país de uma unidade produtora de mercadorias a serem consumidas na Europa (a colônia) para uma comunidade política regida por um contrato social (a nação) passaria evidentemente pela eliminação do passivo da escravidão e por um processo de elevação dos padróes culturais do povo, isto é, a progressiva ocidentalização da população. Para chegar a termo, a formação da nação teria que lidar com essas duas questôes que compóem o nó pós-colonial da sociedade brasileira. Daí a pertinência de se analisar como figuram na argumentação caiopradiana.

Ao longo de Formação do Brasil contemporâneo, há muita imprecisão e flutuação conceitual, o que é característico do ensaio de interpretação nacional. Ora Prado Jr. explica certos fenômenos em decorrência do que considera ser atributo da cultura inferior de certa raça, ora as condiçóes sociais estabelecidas pela escravidão parecem prevalecer no modo como narra o desenvolvimento da história do Brasil. Em determinada passagem, afirma: "As raças escravizadas e assim incluídas na sociedade colonial, mal preparadas e adaptadas, vão formar nela um corpo estranho e incômodo" (Prado Jr., 2000, p. 284). A ênfase aqui recai no adjetivo "escravizadas", que condiciona o modo como tais raças foram incluídas na sociedade colonial, resultando na criação de um "corpo estranho e incômodo". Em passagem anterior do mesmo capítulo, Prado Jr. descreve a escravidão americana como "recrutamento de povos bárbaros e semibárbaros, arrancados do seu hábitat e incluídos, sem transição, numa civilização inteiramente estranha" (Idem, p. 280). Embora as duas passagens refiram-se basicamente ao mesmo processo, a ênfase no segundo trecho incide na caracterização das raças "recrutadas", consideradas bárbaras. Ainda nesse capítulo, o autor disserta sobre o imenso desafio que é absorver o "corpo estranho e incômodo" ao organismo da nação. Argumenta que, ao contrário do que sugeriam os eugenistas brasileiros, o problema da herança colonial não era o legado "étnico" das massas escravizadas. Recorre ao mesmo tom fatalista usado em sua constatação do genocídio indígena para falar que a "eliminação étnica”, embora "demorada, se fez e ainda se faz normal e progressivamente sem maiores obstáculos" (Idem, p. 284). O problema para Prado Jr. não seria o fenótipo racial dos negros e ameríndios, até porque essa questão seria resolvida, "normal e progressivamente", com o embranquecimento gradual dos brasileiros. O que preocupava o autor era "o baixo nível destas massas escravizadas que constituirão a imensa maioria da população brasileira" (Idem, p. 284). O enfoque volta para a condição servil das massas, já que o baixo nível é atribuído ao fato de estarem escravizadas.

Logo em seguida, ao reconstituir a história demográfica brasileira, há um novo deslocamento, pois Prado Jr. sublinha o atraso cultural dos povos que chegavam à colônia: "o tráfico africano se mantinha, [...] despejando ininterruptamente na 
colônia contingentes maciços de populaçóes semibárbaras" (2000, p. 285), criando "este aglomerado incoerente e desconexo, mal amalgamado e repousando em base precárias que é a sociedade colonial" (Idem, p. 285). As consequências para a formação do Brasil não podiam ser piores: do mal amalgamado aglomerado emergiam o baixo teor moral da população e o "baixo nível e ineficiência do trabalho e da produçáo, entregues como estavam a pretos boçais e índios apáticos" (Idem, p. 285). O autor conclui: "O ritmo retardado da economia colonial tem aí uma de suas principais causas" (Idem, p. 285). A ineficiência do trabalho, então, é imputada à boçalidade do negro e à apatia do índio, retomando a explicação baseada em estereótipos raciais.

Para além do vaivém de categorias explicativas, é possível dizer que, no quadro geral da interpretação do Brasil empreendida por Prado Jr. em Formação do Brasil contemporâneo, o aspecto cultural das raças formadoras assume um papel central para explicar o atraso brasileiro, relativizando inclusive o impacto da escravidão. Afinal, está muito claro para o ensaísta marxista que a escravidão não teria o efeito destruidor e paralisante que historicamente teve sobre a sociedade brasileira, se a cultura dos africanos trazidos ao Brasil fosse mais robusta, capaz de suplantar as limitaçóes impostas pelo trabalho servil. Em outras palavras, a escravidão não teria sido tão deletéria para a formação do país, se os escravos fossem outros, que não africanos e índios. Para Prado Jr., "o baixo nível" cultural do negro, "em oposição ao da raça dominante, impediu-lhe de se afirmar com vigor e sobrepor-se à sua miserável condição, ao contrário que em tantas instâncias ocorreu no mundo antigo" (2000, p. 356, grifos nossos). O contraponto com a Antiguidade serve para mostrar que, nesse período histórico, a escravidão "se forneceu de povos e raças que muitas vezes se equiparam a seus conquistadores, se não os superam”, contribuindo "para este com valores culturais de elevado teor” (idem, p. 280). Em última análise, de acordo com o autor, a escravidão não impede o florescimento de uma sociedade, pois as civilizaçóes da Antiguidade eram prova disso. Dessa maneira, as massas semibárbaras escravizadas (mais por serem semibárbaras que escravizadas) comprometeram a formação de uma nação coesa e culturalmente integrada aos valores da modernidade.

Para construir uma naçáo com essas bases precárias, seria necessário elevar o nível cultural da população, seja por meio da educação do "aglomerado incoerente e desconexo", seja por meio da importação de "novos contingentes demográficos". Em $A$ revolução brasileira, de 1966, Prado Jr. faz um elogio à imigração europeia exatamente por ter estimulado "os padrốes culturais da população brasileira" e realizado, desse modo, um aggiornamento cultural no sul do Brasil:

Além disso, a imigração europeia constituiu fator particularmente notável na estimulação de padrôes culturais da população brasileira. $\mathrm{O}$ que tem como comprovação fácil e imediata a grande diferenciação verificada, sob esse aspecto, entre o sul e o norte do país e que se deve em grande senão principal parte à incorporação num caso, e ausência em outro, de apreciáveis contingentes demográficos que se situavam em níveis sensivelmente superiores, culturalmente, aos da preexistente massa da população brasileira (Prado Jr., 2004, p. 85).

As diferenças socioeconômicas que vão se consolidando ao longo do século XX entre sul e norte do país podem ser atribuídas, "em grande senão principal parte", à ida para o sul dos imigrantes europeus, que tinham níveis de cultura sensivelmente superiores aos da população formada pela colonização portuguesa. A questão cultural não é apenas imprescindível para explicar o passivo colonial como também desempenha papel crucial para compreender o desenho do Brasil pós-abolição e prescrever soluçóes para nossos impasses. Em palestra dada na Biblioteca Municipal de São Paulo, em 1946, Prado Jr. ressalta a importância de uma futura imigração que pode ajudar a modernizar o país, corrigindo os defeitos de nossa formação social.

Sem entrar em pormenores de um assunto excessivamente complexo e longo, sou da opinião que a formação social e o desenvolvimento histórico do Brasil foram altamente defeituosos e inconvenientes do ponto de vista dos moder- 
nos padróes e necessidades. Para nos colocarmos hoje no nível da civilizaçáo contemporânea e adquirirmos o ritmo das grandes naçóes da atualidade, precisamos, além de outras reformas profundas do nosso sistema econômico e social, do concurso de novos contingentes demográficos (Prado Jr., 2012, p. 173).

Sem usar a palavra "raça”, Prado Jr. destaca a necessidade "do concurso de novos contingentes demográficos" para, ao lado de outras reformas profundas, colocar o Brasil em sintonia com a "civilização contemporânea”. O que interessava ao autor era um novo comportamento, uma nova ética do trabalho e um valioso estoque cultural que esses contingentes pudessem trazer de seus respectivos países. Desse modo, ajudariam a reformatar culturalmente a população brasileira e abririam caminho para a consolidação da nação moderna.

\section{Conclusão}

Na parte final de Formação do Brasil contemporâneo, Prado Jr. narra como o sistema colonial, com suas contradiçóes internas, começou a entrar em colapso. As transformaçóes estruturais aconteciam, muitas vezes, sob a inspiração da "filosofia da Enciclopédia e dos pensadores franceses do século XVIII” (Prado Jr., 2000, p. 384). Com suas novas ideias, os philosophes forneciam uma interpretação justa e harmoniosa dos "fatos universais do século XVIII", o autor lembra que "universal" se refere à "civilização ocidental a que nos filiamos"(Idem, p. 384), que no Brasil poderiam servir "de lema a todos que pretendiam alguma coisa: senhores de engenho e fazendeiros contra negociantes; mulatos contra brancos; pés-descalços contra calçados; brasileiros contra portugueses" (Idem, p. 386). Prado Jr. ainda observa uma ausência marcante nesse conjunto de antagonismos que emerge da sociedade colonial, transformando-a lentamente:

Faltou apenas "escravos contra senhores", justamente aqueles a quem mais se aplicaria o lema reivindicador; é que os escravos falavam - quando falavam, por que no mais das vezes agiram apenas e não precisaram de roupagem ideológica -, falavam na linguagem mais familiar e acessível que lhes vinha das florestas, dos estepes e dos desertos africanos... (Idem, p. 386).

Formação do Brasil contemporâneo termina com essas palavras, enfatizando a inércia da história brasileira, uma vez que a contradição básica da sociedade colonial, aquela que está no centro de sua atividade econômica, não se traduz em um antagonismo propulsor de mudanças estruturais. As transformações substanciais não aconteceram porque, a despeito de agirem pontualmente ou se rebelarem contra a opressão senhorial, os escravos não conseguiam fazer dessa revolta uma ação política consequente, capaz de construir um novo mundo. E se não agiam de modo construtivo, é porque não falavam uma linguagem política moderna, sintonizada com "os fatos universais do século XVIII" (Prado Jr., 2000, p. 384), cabendo a eles apenas o recurso a um jeito de pensar "que lhes vinha das florestas, dos estepes e desertos africanos" (Idem, p. 386). A contraposição aqui é entre a filosofia enciclopedista, que dá as coordenadas da gramática política moderna, e o pensamento selvagem dos africanos, incapaz de apontar a saída para o quadro de opressão no qual viviam os negros escravizados; exatamente por isso tratava-se de um pensamento inapto para gerar o antagonismo fundamental da sociedade em que viviam. ${ }^{10} \mathrm{~A}$ marcha do desenvolvimento histórico travava em razão do despreparo político dos principais oprimidos do sistema colonial. Não seria exagero afirmar que, para Prado Jr., o escravo era um sujeito pré-político, isto é, um ator social aquém da política moderna.

Essa descrição do final de Formação do Brasil contemporâneo está em perfeita harmonia com o quadro geral de representaçóes tecidas por Prado Jr. sobre os povos não ocidentais no decorrer de sua principal obra. O negro só abandonaria sua suposta passividade e ganhar protagonismo na história brasileira ao ser devidamente ocidentalizado, isto é, quando a gramática política moderna fosse incutida nessa população, permitindo que ganhasse consciência das possibilidades de emancipação social. O subalterno passaria a ser visto quase como uma 
tabula rasa. Ressaltamos o "quase" porque a tabula rasa pressupóe um vazio a ser preenchido. No caso do africano e do ameríndio, é preciso remover o barbarismo inicial para, depois, promover a civilização. Algo semelhante ao que Karl Marx propôs, em 1853, para a Índia colonial, quando afirmou que a Inglaterra tinha lá duas missóes a cumprir: "uma destrutiva, outra regeneradora - a aniquilação da sociedade asiática e a instalação das fundaçôes materialista da sociedade ocidental na Ásia” (p. 1). ${ }^{11}$ Tão importante quanto afirmar o devir-ocidental é negar, destruir e invalidar outros possíveis devires, estando os dois movimentos imbricados no processo formativo da nação ocidental em contexto pós-colonial.

Ainda que atualmente a concepção estereotipada acerca das culturas não ocidentais que formaram o Brasil esteja completamente superada pela historiografia, pela sociologia e pela antropologia contemporâneas, tais refutaçóes não chegam a negar nem a colocar em xeque o peso que Formação do Brasil contemporâneo tem no imaginário político e social brasileiro, sobretudo no campo progressista. Fazemos questão de frisar a palavra progressista, pois a obra de Prado Jr. pode ser considerada progressista de modo coerente e consequente, alinhando-se a uma longa e fecunda tradição do pensamento social brasileiro, que tem figuras como José Bonifácio, Joaquim Nabuco, Silvio Romero, Euclides da Cunha, Monteiro Lobato e tantos outros. Trata-se da linhagem do progressismo que pretende resgatar o negro, o sertanejo, o índio, o jeca-tatu e o caipira da condição de atraso e ignorância que supostamente vivem, para alçá-los a patamares modernos de vida social, "impelindo[-os] para futuro", sem notar que um "amontoado de ruínas cresce até o céu” (Benjamin, 1987, p. 227). Ruínas produzidas não apenas por cadáveres, invasóes, espoliação econômica, como também por constante invalidação e subalternização de suas culturas, de suas imaginaçóes políticas e de seus modos de estar no mundo.

\section{Notas}

1 É importante destacar que a análise do racismo cultural realizada neste artigo está limitada ao grande ensaio de interpretação do país intitulado Formação do Brasil contemporâneo, de Caio Prado Jr. Para um exame mais sistemático e diacrônico da questáo racial na obra desse autor como um todo, seria necessária uma mobilização maior de material, investigando, inclusive, de forma mais detida os manuscritos ainda não publicados que estão nos arquivos do historiador no Instituto de Estudos Brasileiros (IEB) da Universidade de São Paulo (USP).

2 Conforme apontado, trabalho com tendências esquemáticas de recepção, sem a intenção de elaborar um quadro exaustivo da recepção da obra de Prado Jr. Há autores, como Jairo Gonçalves Melo (1987) e Maria Luiza Tucci Carneiro (1989), que habitam zonas ambivalentes em relação a esse assunto, ora elogiando a superação do racismo, ora criticando trechos da obra de Prado Jr. por eles considerados problemáticos.

3 Há aqueles que, diante do debate sobre o racismo cultural de Prado Jr., preferem negar sua existência por meio de artifícios semânticos que, por vezes, se revelam insustentáveis. Para o historiador Lincoln Secco, por exemplo, a expressão "raças inferiores" não "pode ser entendida como manifestaçáo racista do Autor" (2008, p. 174). Segundo o historiador, nos anos de 1930, o adjetivo "inferior" fazia referência à posição subalterna na "hierarquia econômica, social, cultural ou étnica" (Idem, p. 174), esquecendo, no entanto, que Prado Jr. usava outras palavras para se referir a negros e índios: "bárbaro", "semibárbaro", "raça bastarda”.

4 Entre a submissão inicial deste manuscrito e a revisão pedida por pareceristas, foi publicada pelo historiador Paulo Teixeira Iumatti uma obra colossal de história intelectual intitulada História, dialética e diálogo com as ciências (2018), que busca estudar de maneira exaustiva a gênese de Formação do Brasil contemporâneo. O livro ilumina os modos como os contextos sociais, políticos e intelectuais dos anos de 1930 estruturaram o argumento caiopradiano em sua obra principal. Iumatti é o primeiro estudioso sistemático da obra de Prado Jr. que de fato enfrenta a questáo do racismo cultural. Ao longo do artigo, estabeleço alguns diálogos com esse texto, ora para afirmar algumas diferenças de abordagem, ora para recorrer à erudição de suas análises. Fica o registro do ineditismo e da robustez do trabalho de Iumatti.

5 O devir-índio e o devir-negro figuram no pensamento brasileiro como verdadeiros fantasmas, temidos por muitos intelectuais. O devir-índio é comumente imaginado com base em uma hipotética vitória dos jesuítas no processo de colonizaçáo do Brasil, trans- 
formando o país em um imenso Paraguai, jesuítico e guarani. Podemos ver a sombra desse fantasma em alguns trechos de Formação do Brasil contemporâneo, de Prado Jr., em $O$ abolicionismo, de Joaquim Nabuco, e na obra do historiador português Joaquim Pedro de Oliveira Martins, para quem, se "os jesuítas tivessem vencido, o Brasil seria, como esse miserável canto do mundo [o Paraguai], povoado por uma raça inferior que só perde os instintos de fera selvageria para cair num torpor de cretinismo idiota" (1978, p. 72). Já o devir-negro é marcado pelo temor de uma replicação da Revolução Haitiana no Brasil, isto é, o medo de os escravos se libertarem, punirem seus senhores e assumirem o comando político do país. O medo do Haiti está no escrito de vários publicistas brasileiros do século XIX, especialmente nos ensaios de José da Silva Lisboa, o visconde de Cairu (cf. Monteiro, 2003). Ladeando o devir-ocidental, estudado neste artigo, há os fantasmas de outros devires que devem ser constantemente exorcizados pela elite ilustrada brasileira. $\mathrm{O}$ uso dos devires para pensar a formaçáo social brasileira é inspirado na reflexáo do antropólogo Eduardo Viveiros de Castro (2015) sobre o devir-índio.

6 O historiador Reinhart Koselleck associa a mirada comparativa que transforma diferenças sincrônicas em estágios civilizatórios a uma era que se torna possível com os descobrimentos: "A abertura geográfica do globo trouxe luz a vários e coexistentes níveis culturais que, por meio do processo de comparação sincrônica, passaram a ser entáo ordenados diacronicamente. Olhar da civilizada Europa para uma América bárbara representava uma mirada para trás, para o passado [...] Comparações promoviam uma visão de história mundial que era crescentemente interpretada em termos de progresso" (2004, p. 238, tradução nossa).

7 Alice L. Conklin afirma que, na França dos anos de 1930, "o estudo biológico e o ranqueamento de raças humanas ainda eram considerados ramos perfeitamente legítimos das ciências humanas" (2013, p. 1, tradução nossa). A autora investiga o nexo entre antropologia francesa, evolucionismo e a obsessão por classificação racial, sobretudo na constituiçáo do Musée de l'Homme, em Paris (França). George Montandon é um dos autores examinados no estudo.

8 A fantasia da "extinçáo total" dos ameríndios parecia circular entre a elite letrada e política dos anos de 1930 e 1940. Claude Lévi-Strauss, ao apresentar suas memórias de viagem em Tristes trópicos (1957), relata o encontro que teve, em 1934, com o embaixador do Brasil na França. O autor depara com a fantasia da "extinçáo total" dos ameríndios na fala de Luis Mar- tins de Sousa Dantas, que responsabilizava os portugueses pelo extermínio da população nativa. Lévi-Strauss se pergunta como tal ignorância seria possível e chama a atenção para as matanças de indígenas no início século XX, o que era ocultado na fala de Sousa Dantas.

9 Como observa Iumatti, o racismo cultural de Prado Jr. "corresponde a uma noção de civilização que tomava como modelo superior não só a ciência e a tecnologia do mundo capitalista e da URSS, mas ainda a civilização e cultura do mundo antigo" (2018, p. 298), o que explica, ainda segundo o autor, Prado Jr. ter "um aproveitamento táo baixo do ponto mais importante da obra de Gilberto Freyre: a valorizaçáo afro" (Idem, p. 298). Em Casa-grande \& senzala, que Freyre publicou em 1933, há uma valorização da contribuição imaterial (simbólica, cultural, na dança, na música, no jeito de contar histórias etc.) e material (gastronomia, técnicas de metalurgia, de criaçáo de gado etc.) do negro à cultura brasileira.

10 O recurso ao "baixo nível intelectual" dos escravos para explicar sua inação política pode ser encontrado já na primeira obra de Prado Jr., Evolução política do Brasil: "Os escravos, além de seu baixo nível intelectual - grande parte vinha diretamente das selvas africanas, e por isso em nada se diferenciava das populaçóes ainda em completo estado de barbaria de que provinha - eram divididos por profundas rivalidades tribais que traziam de seu habitat de origem" (2012, p. 64).

11 É importante ressaltar que o artigo "The British rule in India" evidencia um momento de crença na inexorabilidade das forças transformadoras do capitalismo, que solapariam velhas estruturas sociais. Tal celebração das mudanças progressivas trazidas pelo capitalismo também pode ser vista em Manifesto comunista, de Friedrich Engels e Karl Marx, por exemplo. Ao longo dos anos, a abordagem que Marx faz das culturas não ocidentais e sua relação com o capitalismo muda de ênfase. Livros como os de Kevin Anderson (2010) e Marcello Musto (2018) são importantes para mostrar essa mudança, discrepando assim de uma interpretação que atribuía a Marx um etnocentrismo constante ao longo dos anos (Avineri, 1968; Said, 1978).

\section{BIBLIOGRAFIA}

ANDERSON, Kevin. (2010), Marx at the margins: on nationalism, ethnicity and non-Western societies. Chicago, University of Chicago Press. 
ANDRADA E SILVA, José Bonifácio. (2000), Projetos para o Brasil. Sáo Paulo, Companhia das Letras.

AVINERI, Shlomo. (1968), The social and political thought of Karl Marx. Cambridge, Cambridge University Press.

BALIBAR, Etienne. (1991), "Is there a neo-racism?", in E. Balibar \& I. Wallerstein, Race, nation, class: ambiguous identities, Londres, Verso, pp. 17-28.

BENJAMIN, Walter. (1987), "Teses sobre o conceito de história, 1940", in W. Benjamin, Magia e técnica, arte e politica: ensaios sobre literatura e história da cultura, Tradução de Sérgio Paulo Rouanet, São Paulo, Brasiliense, pp. 222-232.

CANDIDO, Antonio. (1995), "O significado de Raízes do Brasil", in S. B. de Holanda, Raizes do Brasil, São Paulo, Companhia das Letras, pp. 9-22.

CARNEIRO, Maria Luiza Tucci. (1989), "A questẫo racial”, in M. A. D'Incao, História e ideal: ensaios sobre Caio Prado Junior, São Paulo, Editora Unesp, pp. 347-354.

CONDORCET [Marie-Jean-Antoine-Nicolas de Caritat]. (2013), Esboço de um quadro histórico dos progressos do espírito humano. Tradução de Carlos Alberto Ribeiro de Moura. Campinas, Editora da Unicamp.

CONKLIN, Alice L. (2013), In the museum of man: race, anthropology and empire in France, 1850-1950. Ithaca, Cornell University Press.

COSTA, Emília Viotti. (1998), Da Monarquia à República: momentos decisivos. São Paulo, Editora Unesp.

FANON, Frantz. (1968), Os condenados da terra. Tradução de José Laurênio de Melo. Rio de Janeiro, Civilização Brasileira.

HOLANDA, Sérgio Buarque de. (1995), Raizes do Brasil. São Paulo, Companhia das Letras.

IGLÉSIAS, Francisco. (1982), "Um historiador revolucionário”, in F. Iglésias (org.), Caio Prado Júnior: história, São Paulo, Ática, pp. 12-27.

IUMATTI, Paulo Teixeira. (2018), História, dialética e diálogo com as ciências: a gênese da Formação do Brasil contemporâneo, de Caio Prado Jr. (1933-1942). São Paulo, Intermeios.
KOSELLECK, Reinhart. (2004). Futures past: on semantics of historical time. Tradução de Keith Tribe. Nova York, Columbia University Press.

LEITE, Dante Moreira. (1976), O caráter nacional brasileiro. São Paulo, Difel.

LÉVI-STRAUSS, Claude. (1957), Tristes trópicos. Tradução de Wilson Martins. São Paulo, Editora Anhembi.

MARTINS, Joaquim Pedro de Oliveira. (1978), O Brasil e as colónias portuguesas. Lisboa, Guimarães.

MARX, Karl. (1853), "Os resultados eventuais da dominação britânica na Índia”. Tradução de Jason Borba. Disponível em http://www.dominiopublico.gov.br/download/texto/ma000073. pdf, consultado em 15/11/2019.

MELO, Jairo Gonçalves. (1987), "O economicismo em Caio Prado Jr". Novos Estudos CEBRAP, 18: 42-48.

MONTEIRO, Pedro Meira. (2003), "Cairu e a patologia da revolução”. Estudos Avançados, 17 (49): 349-358.

MOTA, Carlos Guilherme. (2008), Ideologia da cultura brasileira (1933-1974): pontos de partida para uma revisão histórica. São Paulo, Editora 34.

MUSTO, Marcello. (2018), O velho Marx: uma biografia de seus últimos anos (1881-1883). Tradução de Rubens Enderle. São Paulo, Boitempo.

NABUCO, Joaquim. (2000), O abolicionismo. São Paulo, Publifolha.

PRADO JR., Caio. (2012), Evolução política do Brasil e outros estudos. São Paulo, Companhia das Letras.

PRADO JR., Caio. (2000), Formação do Brasil contemporâneo. São Paulo, Brasiliense.

PRADO JR., Caio. (2004), A revolução brasileira. São Paulo, Brasiliense.

RICUPERO, Bernardo. (2000), Caio Prado Jr. e a nacionalização do marxismo no Brasil. São Paulo, Martins Fontes.

SAID, Edward W. (1978), Orientalism. Nova York, Vintage Books.

SANTIAGO, Silviano. (2000), "Intérpretes do Brasil”, in S. Silviano (org.), Intérpretes do Brasil, Rio de Janeiro, Nova Aguilar, pp. 6-51. 
SANTIAGO, Silviano. (2006), Ora (direis) puxar conversa!: ensaios literários. Belo Horizonte, Editora UFMG.

SCHWARZ, Roberto. (1999), Sequências brasileiras: ensaios. São Paulo, Companhia das Letras.

SECCO, Lincoln. (2008), Caio Prado Júnior: o sentido da revolução. São Paulo, Boitempo.

SPENCER, Herbert. (1882), The principles of sociology. Nova York, D. Appleton \& Co., vol. 2.

STOCKING JR., George W. (1968), Race, culture and evolution: essays in the history of anthropology. Nova York, The Free Press.

VAINFAS, Ronaldo. (1999), "Colonização, miscigenação e questão racial: notas sobre equívocos e tabus na historiografia brasileira”. Tempo, 8: $1-12$.

VIVEIROS DE CASTRO, Eduardo. (2015), “O índio em devir” in M. Herrera e U. Fernandes. Baré: povo do rio. São Paulo, Ediçóes Sesc. 


\section{RAÇA E MODERNIDADE EM FORMAÇÁO DO BRASIL CONTEMPORÂNEO, DE CAIO PRADO JR.}

\section{Alfredo Cesar B. de Melo}

Palavras-chave: Caio Prado Jr.; Racismo; Modernidade; Colonialismo; Progresso.

Neste artigo argumentamos que a principal obra de Caio Prado Júnior estabelece uma clara hierarquização de culturas para interpretar o Brasil, dentro da qual a ocidental assume o protagonismo das transformaçóes históricas, enquanto as culturas não ocidentais da matriz colonial brasileira (africanas e ameríndias) são avaliadas como coadjuvantes de pouca expressão para a construçấo do Brasil moderno. Pretendemos mostrar que, na obra Formação do Brasil contemporâneo, o país só poderia consolidar sua formação por meio de um processo de modernização/ocidentalização cultural.

\section{RACE AND MODERNITY IN FORMAÇÃO DO BRASIL CONTEMPORÂNEO BY CAIO PRADO JR.}

\section{Alfredo Cesar B. de Melo}

Keywords: Caio Prado Jr.; Racism, Modernity; Colonialism; Progress.

In this article we argue that Caio Prado Júnior's main work sets a clear sense of hierarchy of cultures in order to interpret Brazil. In this interpretive framework, Western culture takes leadership over historical transformations. In contrast, the non-Western cultures of Brazilian colonial matrix (African and Amerindian) are considered to play a minor role in the nation-building of modern Brazil. We intend to show that, according to the book Formação do Brasil contemporâneo, Brazil would only become a modern nation through a process of cultural westernization.

\section{RACE ET MODERNITÉ DANS FORMAÇÃO DO BRASIL CONTEMPORÂNEO DE CAIO PRADO JR.}

Alfredo Cesar B. de Melo

Mots-clés: Caio Prado Jr.; Racisme; Modernité; Colonialisme; Progrès.

Dans cet article, nous soutenons que l'œuvre majeure de Caio Prado Junior établit une très nette hiérarchisation entre les cultures pour interpréter le Brésil, à l'intérieur de laquelle la culture occidentale assume un protagonisme des transformations historiques, tandis que les cultures non occidentales de la matrice coloniale brésilienne (africaines et amérindiennes) sont évaluées comme de simples seconds rôles pour la construction du Brésil moderne. Nous souhaitons démontrer que dans Formaçáo do Brasil contemporâneo (Formation du Brésil contemporain) le pays ne pourrait consolider sa formation qu'à travers un processus de modernisation/d'occidentalisation culturelle. 